\author{
Military Technical College \\ Kobry El-Kobbah, \\ Cairo, Egypt
}

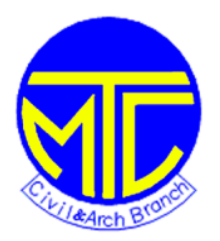

\title{
NUMERICAL ANALYSIS OF THE BEARING CAPACITY OF FOOTINGS ON SAND REINFORCED WITH WRAPPED CUSHIONS
}

$$
\text { By }
$$

Nabil NAGY ${ }^{1}$

Mostafa MOHAMED $^{2}$

\section{ABSTRACT}

The construction of many civil engineering structures is hindered by the poor condition of near-surface soils. Structures built on loose sands or weak clays always undergo excessive settlement. Thus, measures should be undertaken to improve the shear strength characteristics of these soils in order for safe and economic structures to be built. In situ treatment has evolved markedly with soil reinforcement using planner layers of geosynthetic as one of the well developed techniques. The behaviour of conventionally reinforced soils depends mainly upon the frictional resistance between reinforcing layers and surrounding soil. In this paper, an alternative approach is proposed and examined for improving the bearing capacity of weak soils. The proposed technique involves wrapping the soil underneath the footings by a layer of geosynthetic in order to create a wrapped cushion. Results of numerical investigation carried out using a finite element code "ABAQUS" are presented and validated against physical experiments. The elasto-plastic Drucker-Prager Cap model is used to model the soil behaviour. The interaction between reinforcing material and surrounding soil and between footing and reinforcing material is modelled using "Contact pair" models. The results of the proposed technique seem promising over the conventional soil reinforcement technique

\footnotetext{
${ }^{1}$ Lecturer in Geotechnical Engineering, Military Technical College, Kobry Elkobba - Cairo, Egypt. nabilmnagy@yahoo.com

${ }^{2}$ Lecturer in Geotechnical Engineering, School of Engineering, Design and Technology, University of Bradford, Bradford, UK. Email: m.h.a.mohamed@ bradford.ac.uk
} 


\section{Introduction:}

Weak soils such as loose sands and soft clays are characterised by the low bearing capacity value and excessive settlement even under small loading conditions. Collapsible soils always pose risk to structures built on. Several techniques such as dynamic compaction, chemical treatment and soil reinforcement, emerged for improving the load-settlement behaviour of these soils. Reinforcement of weak soils is an effective and relatively cheap method for enhancing the behaviour of these soils under loading and their long-term stability. Many studies have investigated the influence of soil reinforcement on the stability of slopes and earth retaining structures. This work has been extended for enhancing the bearing capacity of weak and collapsible soils as well as for minimising the associated settlement (see for example, Binquet and Lee, 1975 (b), Guido, et al. 1986 and Alawaji 2001).

The behaviour of reinforced soils depends primarily upon the frictional resistance between the horizontal ties and the surrounding soils. Thus, the use of granular soil packing between woven geotextile layers is preferable (Saleh, 2001). In addition to the frictional resistance between the soil and the reinforcing layers, configuration of reinforcing layers including the number, location and dimension of layers, has significant influence on the behaviour of reinforced ground.

Several researchers concluded that placing the reinforcement layers below a depth of the footing width is not beneficial (see for example, Chang 1985 and Guildo et al. 1986). However, there is a debate for the optimum depth of the geotextile layers. The optimum depth of the top layer of reinforcement was found to vary between 0.1 and 0.5 of the footing width depending upon the test conditions and materials used (see for example, Akinmusuru and Akinbolade, 1981, Yetimoglu et al., 1994 and Yamamoto and Otani 2002). The number of reinforcement layers is also extensively investigated. In general, the bearing capacity increases with increasing the number of layers up to a certain number. The results of Yetimoglu et al. (1994) suggested that the optimum number of layers is 4 whereas Guildo et al. (1986a) recommended the use of 3 layers. It should be noted that a marginal increase in the value of ultimate bearing capacity is observed even with further increase in the number of layers above the recommended one.

The vertical spacing between the successive layers of reinforcement also plays a significant role in the bearing capacity of reinforced ground (see for example, Guildo et al. 1986b and Singh 1988). In principal, it was found that there is an optimum vertical spacing between the reinforcement layers, which would vary between 0.15 and 0.25 of 
the footing width. If the vertical spacing between reinforcing layers increases, less interaction between them could be manipulated which in turn would affect significantly the value of bearing capacity. Besides the vertical spacing between reinforcing layers, the dimension of layers affects the overall performance of the reinforced ground.

The size of the reinforcing layers depends upon the type of reinforcement and shape of footing with greater dimension of reinforcement needed for strip footing over ground reinforced with geotextile layers (see, for example, Guildo et al. 1986). Results indicated that the geogrid reinforcement is more effective than the geotextile from the standpoint of improving the bearing capacity of footing on reinforced sand (Guildo et al. 1986). Jewel et al. (1984) pointed out that the mechanism for mobilization of friction resistance in geogrids was different from that of geotextile. Various deformation patterns of reinforced sand beds at failure were studied (Michalowski and Shi 2003).

It comes clear that the behaviour of reinforced soils depends upon the mobilised frictional resistance between the reinforcing layers and surrounding soils as well as the mobilised tensile force in the reinforcing layers. The latter would depend upon the type and arrangement of the reinforcing layers. By examining the conventional method of reinforcement, it is clear that the use of strong reinforcing layers is not beneficial, as the overall performance of soil and reinforcement would be restricted by the mobilised frictional resistance.

Thus, an alternative technique is proposed to exploit the reinforcement material to its maximum possible strength. The proposed technique involves wrapping a layer of geotextile around a nominal amount of soil in order to create a wrapped and sealed cushion underneath the surface footing. The proposed method would depend primarily upon the tensile strength of the geotextile material as well as the density of soil within the cushion. In addition it depends secondarily upon the frictional resistance between cushion and the surrounding soil.

In this paper, the results of the numerical and experimental investigations carried out to examine the efficiency of the proposed technique are presented. It is found that the proposed technique further enhances the performance of poor soils when it is compared with the conventional reinforcement method. Further investigations are underway to explore the influence of joints and filling material on the load-settlement behaviour. 
Materials and experimental set-up

An experimental investigation was carried out to investigate the behaviour of unreinforced sand beds and sand beds reinforced with geotextile layers or wrapped geotextile cushions, under surface loading. Figure 1 shows the experimental set-up employed in this investigation. A rigid 3-D tank with internal dimensions of $50 \mathrm{~cm} \times 50$ $\mathrm{cm} \times 40 \mathrm{~cm}$ was used to construct sand media. A square rigid steel plate with a dimension of $10 \mathrm{~cm}$ x $10 \mathrm{~cm}$ was used to transfer the vertical load. The vertical load is applied via the loading device, which is mounted on the loading frame. The applied load and settlement of the footing were recorded electronically using the data acquisition system.

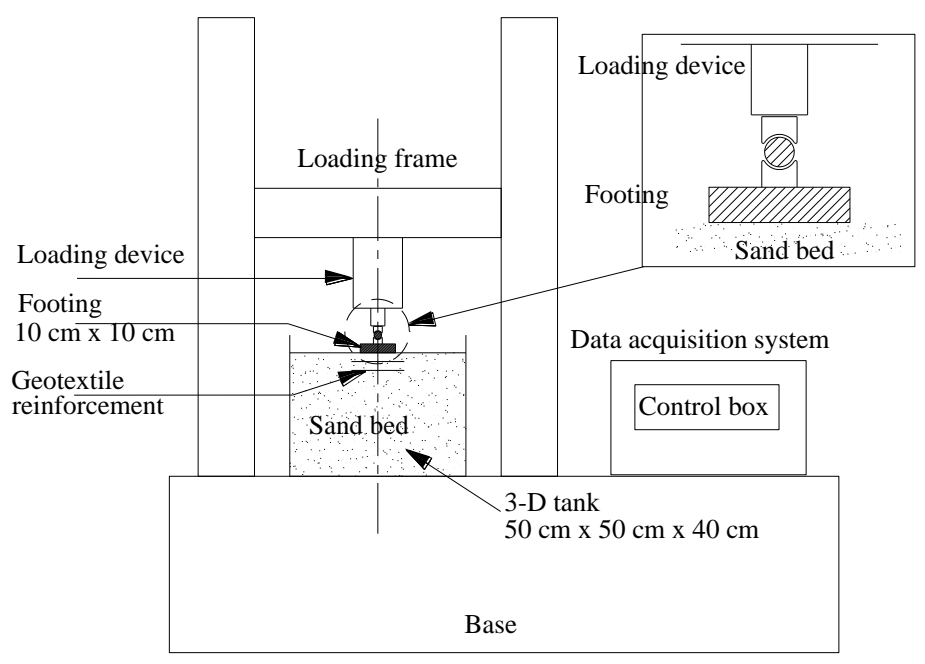

Figure 1: Experimental set-up

Dry silica sand was used in this investigation. This sand was classified as poorly graded medium sand $\left(\mathrm{C}_{\mathrm{u}}=1.18\right.$ and $\left.\mathrm{C}_{\mathrm{c}}=1.0\right)$ with $\mathrm{D}_{50}$ of $0.37 \mathrm{~mm}$. The measured density of all sand samples was $\sim 1.56 \mathrm{gm} / \mathrm{cm}^{3}$. A Lotrok $50 \mathrm{R}$ woven geotextile material was used to reinforce the sand beds. The Lotrok 50R was used because of its high tensile resistance and small pore size distribution of the geotextile sheet, which holds the sand particles within the wrapped cushion without any troubles. Square reinforcing layers were placed as required by the test condition. Shear box tests were undertaken to determine the angle of shearing resistance of sand samples and between the sand and Lotrok 50R sheets. The angles of shearing resistance are $32^{\circ}$ and $30^{\circ}$ for sand samples and between the sand and geotextile layer respectively. 
Test programme and procedure

In all experiments, dry sand was poured inside the 3-D tank from a height of $50 \mathrm{~cm}$ above the sand level to construct homogenous sand packing. The process continued up to reaching the predetermined level of the geotextile layers. Then the sand surface was horizontally levelled. Subsequently a layer of geotextile or the wrapped cushion was placed at that level. At this stage, care was taken to place the reinforcement symmetrically around the vertical centreline of the tank. It should be noted that the wrapped cushion was prepared and sealed properly using staples to maintain adequate tensile strength between various parts of the cushion before its placement within the sand bed. Subsequently, dry sand was poured again either to reach another level in order to place a second reinforcing layer or to fill the rest of the tank. Finally, the sand surface was levelled off. The steel plate representing the surface footing was placed carefully on the sand surface and proper arrangements were implemented to ensure that the vertical centreline of the footing coincides with that of the reinforcing layers and the footing sides are parallel to those of the reinforcing layers in their horizontal projection.

Identical sand beds were almost constructed.

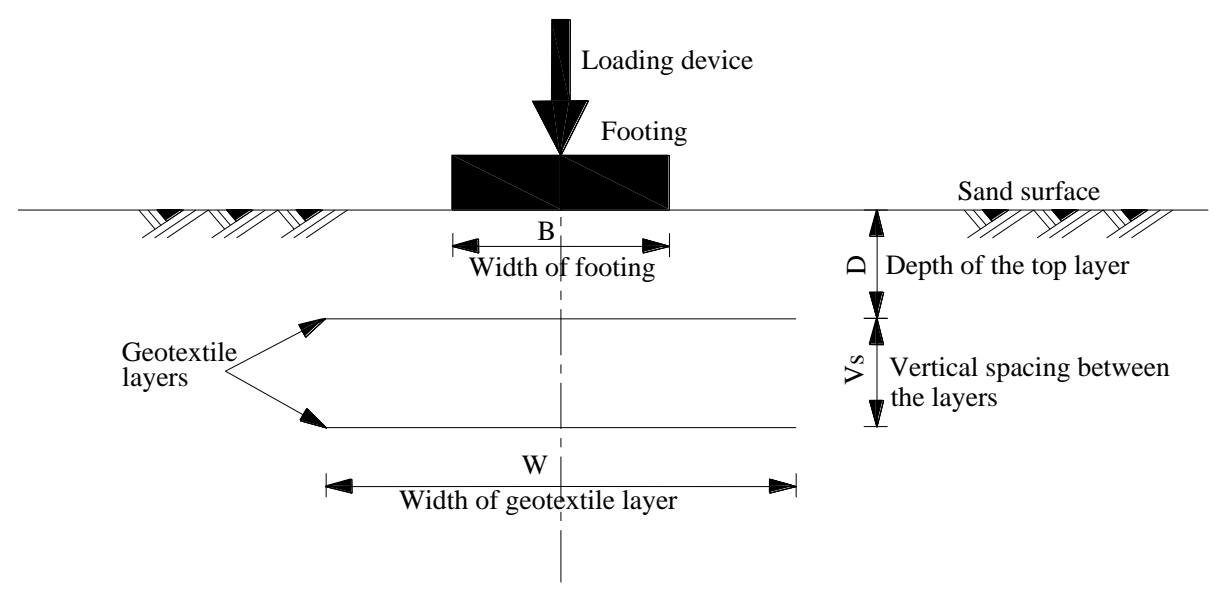

Figure 2: Different parameters studied

Initial tests were carried out on unreinforced sand beds to determine the load-settlement behaviour. Then a series of tests was carried out to investigate the influence of the depth of the top geotextile layer or the top of the geotextile cushion below the sand surface (D); the vertical spacing between the geotextile layers or the equivalent thickness of the geotextile cushion (Vs) and the width of the geotextile layer or cushion (W) on the loadsettlement behaviour. Figure 2 shows different parameters studied in this investigation. 
In total 34 tests were conducted with various values of $\mathrm{D}$, Vs and $\mathrm{W}$. The results of reinforced sand beds were referenced to those of unreinforced sand beds.

\section{Numerical Modelling}

\section{Description of the model}

In this study, the non-linear finite element package ABAQUS/Standard is used to carry out a two-dimensional (2D) plain strain analysis of the model. Finite Element Method is applied for investigating the using of geotextile sheets for improving the bearing capacity of weak and problematic soils underneath the surface footing. A numerical model is developed so that the considered problem can be investigated. An elaborated description of the models assigned for soil mass, surface footing, geotextile wrapped cushion and Soil-Geotextile interface is presented in this section. Four-node bilinear plane strain quadrilateral reduced integration elements () are used to discretize the soil, while 2-node linear membrane elements are used to discretize the reinforcement. Number of finite element meshes with different degrees of refinement was tried first in order to obtain appropriate mesh for the analysis of the system that converges to a unique solution as denser mesh is constructed in areas in which stresses are concentrated. The finally adopted finite element model for the problem is illustrated in Figure 3,

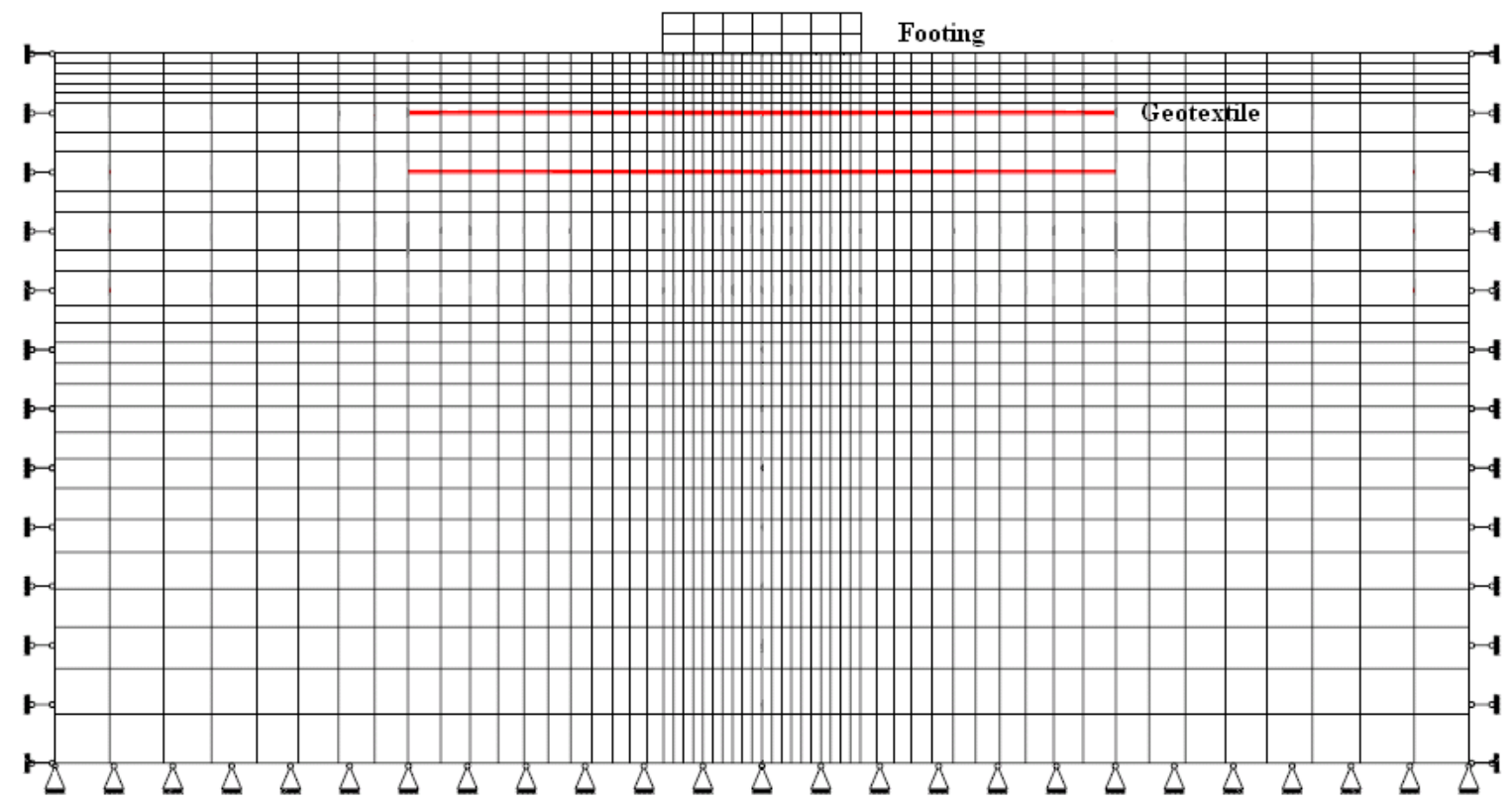

Figure 3: Finite element mesh 


\section{Process of Loading and Boundary Conditions}

The footing is modelled as steel, rigid and perfectly bonded to the soil surface. The external uniform pressure loading process on the footing is applied continuously incrementally until the prescribed displacement is attained. The boundary conditions are utilized to reproduce those of experimental tests. On the two sides of model, the displacement in the horizontal direction is restrained. At the bottom surface of the model no normal and tangential displacement are allowed, whereas the top surface of the model is free of restrain.

\section{Soil and Reinforcement Modelling}

A membrane element is the most suitable element for the modelling of the geosynthetics (Perkins, 2001) and was used by many researchers (e.g. Dondi, 1994; Lee, 2000). So in this numerical investigation, the reinforcement is simulated as a membrane, which transmits in-plane force only and has no bending stiffness. The stress-strain behaviour of reinforcement is modelled by a linear elastic model. The soil is considered as a sand soil whose behaviour is modelled by an elasto-plastic Drucker - Prager Cap model. The Drucker-Prager-Cap model was originally developed to predict the plastic deformation of soils under compression (Mizuno and Chen, 1990). It consists principally of two intersecting segments: a shear failure segment $F s$ and a cap segment $F c$ which provides an inelastic hardening mechanism to account for plastic compaction and helps to control volume dilatancy when the material yields in shear. A transition segment $F t$ has been introduced to provide a smooth surface between the shear failure surface and cap segment.

\section{Soil- Reinforcement Interface Model}

The soil-reinforcement interface properties are one of the basic factors influencing the performance of reinforced soil foundation. The surface-based contact interaction available in Abaqus/Standard is used in this study to model the soil-reinforcement interface. Surface-based contact simulations between two deformable bodies generally need to define mechanical contact property models in two directions normal and tangential directions. the "hard contact" is assumed in normal direction and no separation of surfaces is allowed once surfaces contact. These contact properties in normal direction can minimize the penetration of slave nodes into the master surface and don't allow the transfer of tensile stress across the interface. The contact pressures transmitted across the interface usually are shear and normal forces. The relationship 
between these two force components is described in terms of the Coulomb friction model

\section{Results and discussion}

The results of the experimental investigation are presented here to highlight the effect of wrapping a sand cushion with a layer of geotextile on the behaviour of the sand bed. To examine the efficiency of such reinforcement, the percentage increase in bearing pressure, is employed. The percentage increase in bearing pressure is defined as:

$\%$ increase in bearing pressure $=\frac{\mathrm{q}_{\mathrm{r}}}{\mathrm{q}_{\mathrm{o}}} \times 100$

(1) where

$\mathrm{q}_{\mathrm{r}}$

and $\mathrm{q}_{\mathrm{o}}$ are the maximum bearing pressure of reinforced and unreinforced sand beds respectively. The bearing pressure is the load in $\mathrm{kN}$ divided by the area of the footing $\left(100 \mathrm{~cm}^{2}\right)$. For convenience in expressing and comparing the data, the maximum bearing pressure was taken at a settlement of $25 \mathrm{~mm}$ in all tests.

Figure 4 shows the bearing pressure against settlement of unreinforced sand bed and reinforced sand bed with two geotextile layers with different values of vertical spacing. This batch of tests was carried out while maintaining a depth of $0.25 \mathrm{~B}$ between the sand surface and top geotextile layer and width of geotextile layers as the same as the footing width. It is clear from Figure 4 that the bearing pressure of unreinforced sand bed is much smaller than that of the reinforced sand bed at the same settlement. These results show clearly that as the vertical spacing between the two geotextile layers increased the maximum bearing pressure decreased. At a vertical spacing of $0.25 \mathrm{~B}$, the maximum bearing pressure was the greatest $\left(82 \mathrm{kN} / \mathrm{m}^{2}\right)$ an improvement of $95 \%$ over unreinforced sand bed. The least maximum bearing pressure $\left(64 \mathrm{kN} / \mathrm{m}^{2}\right)$ corresponds to a vertical spacing of $1 \mathrm{~B}$, an improvement of $52 \%$. These results are in good agreement with previously reported ones (see, Singh, 1988 and Yetimoglu et al 1994). 


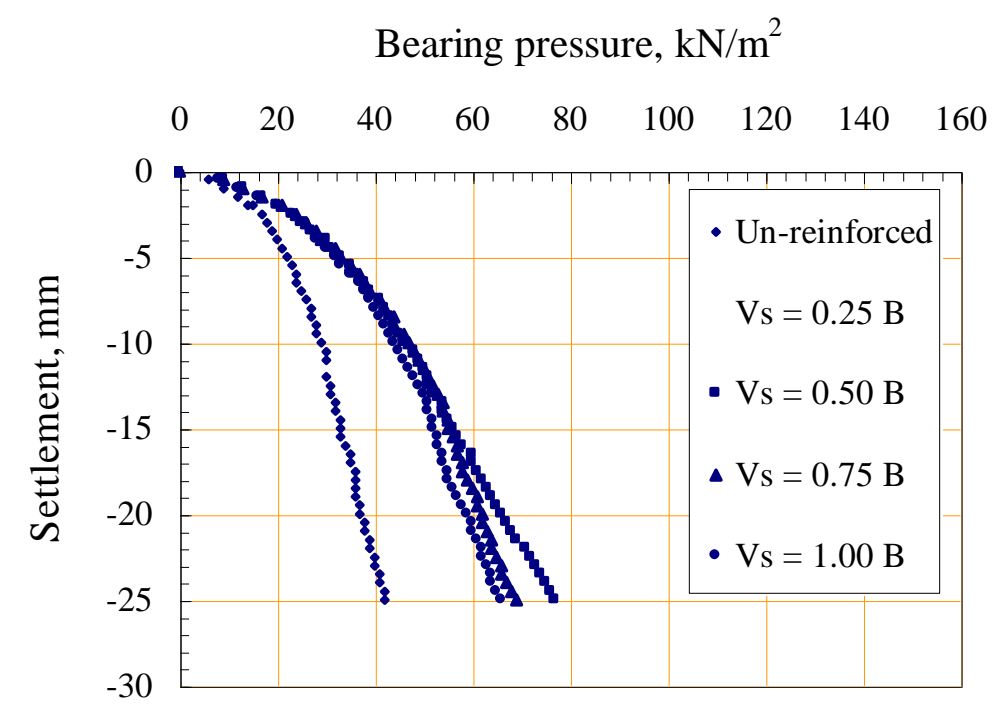

Figure 4: Influence of increasing the vertical spacing between two geotextile layers on the load-settlement behaviour of reinforced sand beds.

\section{Finite Element Model Verification}

In order to validate the correctness of the adopted models for the soil, reinforcement, and reinforcement-soil interaction, finite element analyses were first checked against the results from experimental model tests for a footing on the reinforced soil. Figures 5-7 show the comparison between the finite element analyses and the experimental model tests for unreinforced and two-layer reinforced soil with different values of vertical spacing $(0.25 \mathrm{~B}$ and $1 \mathrm{~B})$. As can be seen from these figures, the finite element analyses have a reasonable agreement with model test results, although there is some allowable deviation between them.

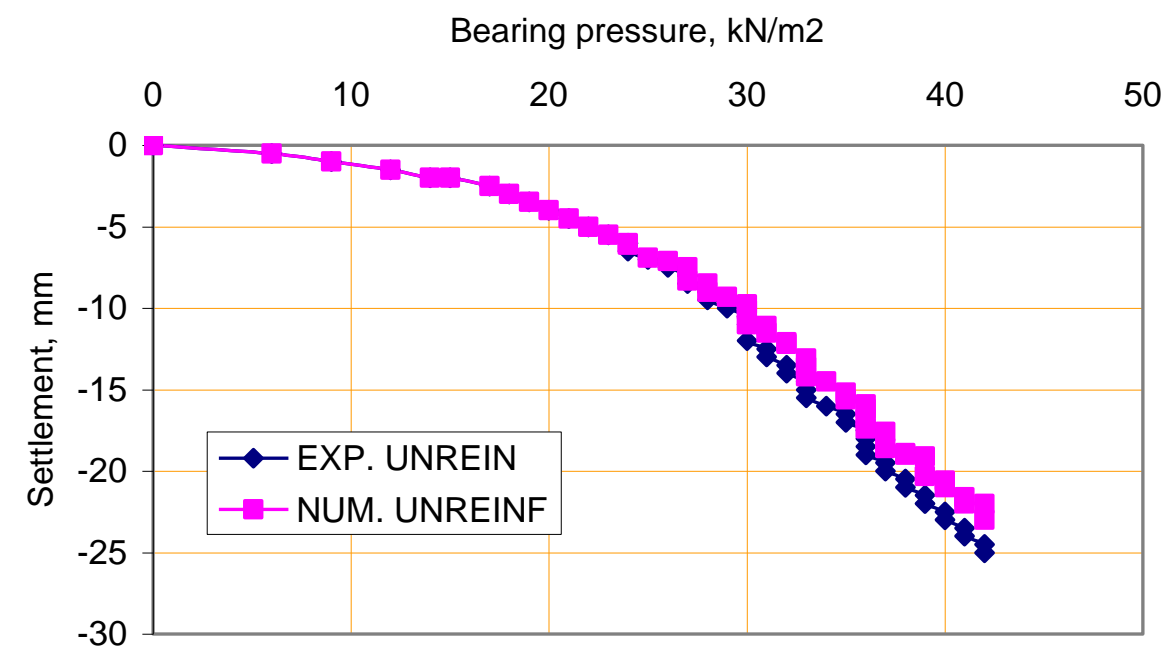

Figure 5: Model Verification for unreinforced soil 


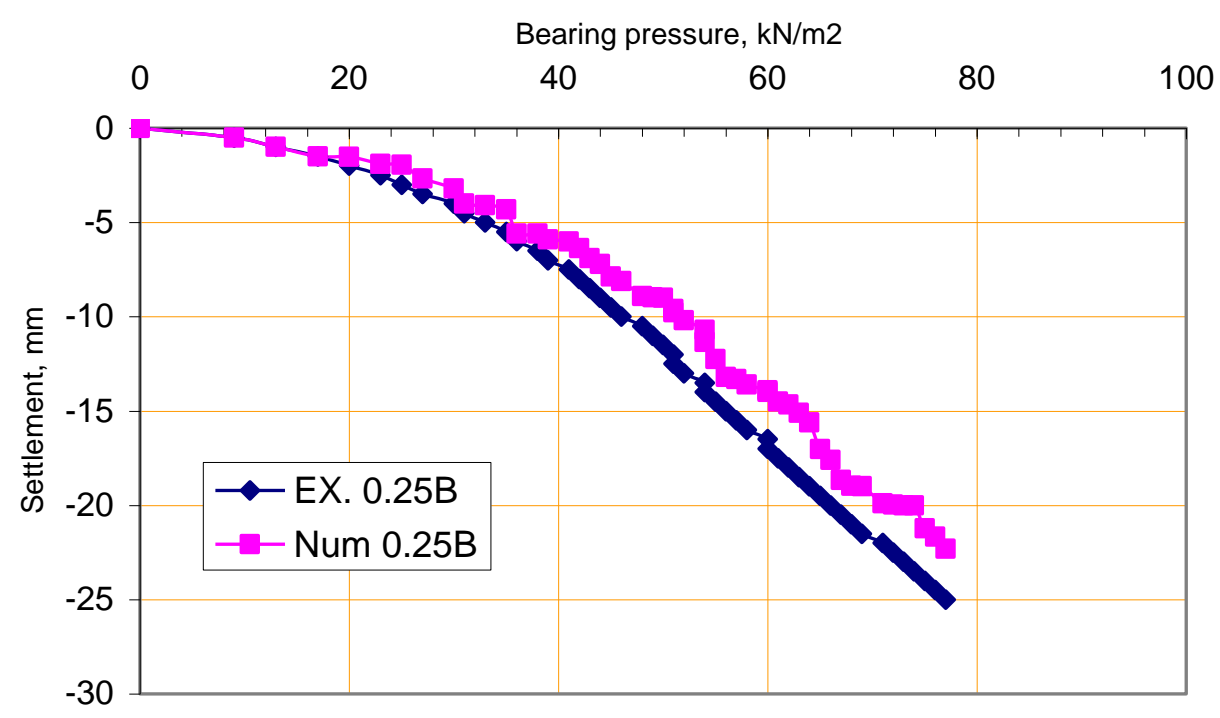

Figure 6: Model Verification for reinforced soil (025 B)

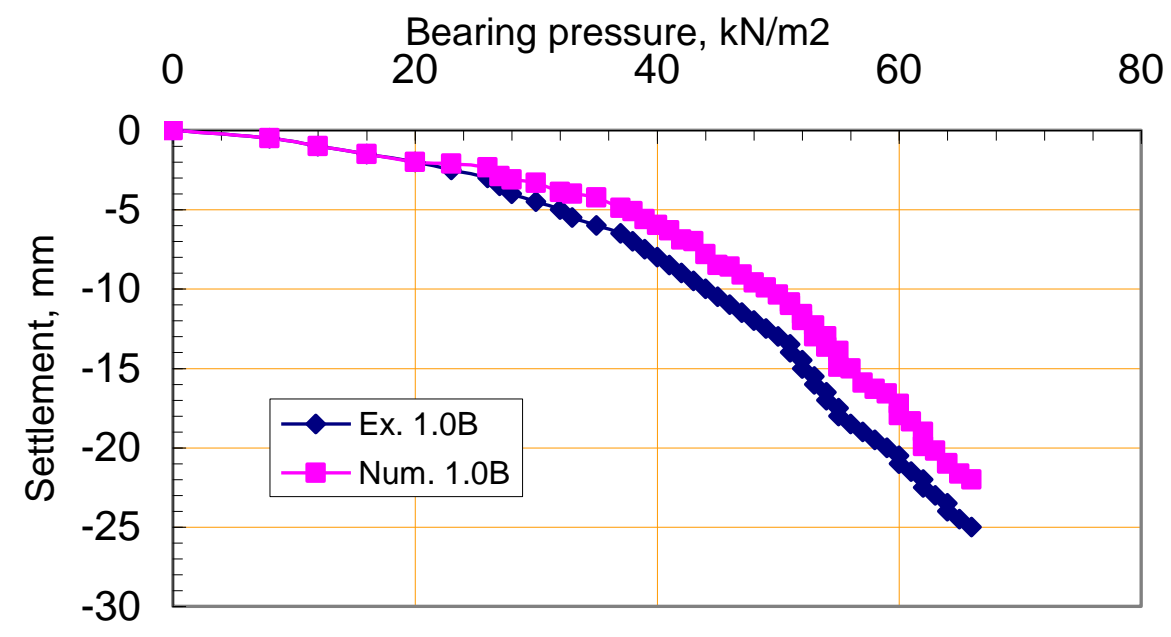

Figure 7: Model Verification for reinforced soil (1.0B)

Results of sand beds reinforced with wrapped cushions of different thicknesses are presented in Figure 8. Figure 8 shows clearly that significant increase in the maximum bearing pressure was noticed with increasing the thickness of wrapped cushion.

For example, an improvement of $320 \%$ was obtained when the thickness of wrapped cushion was $1.0 \mathrm{~B}$. To aid the discussion and to compare the data presented in Figures 4 and 8 , the percentages increase in maximum bearing pressure for both reinforcement methods at various values of vertical spacing are shown in Figure 9. It can be seen that the sand beds reinforced with wrapped cushions have completely opposite behaviour pattern to those reinforced with two layers of geotextile. There are several factors contributed to the increase in maximum bearing pressure including: 
1. The wrapped cushion transfers the surface loading to a deeper level, which results in greater bearing capacity.

2. Vertical deformation of the wrapped cushion increases the density of the cushion, as the surface area of the wrapped cushion remains constant. This increases the stiffness of wrapped cushion, which in turn increases the bearing capacity.

3. With thicker wrapped cushion, more shear resistance is developed along the sides of the cushion. These sides resistance increase the bearing capacity and decreases the settlement.

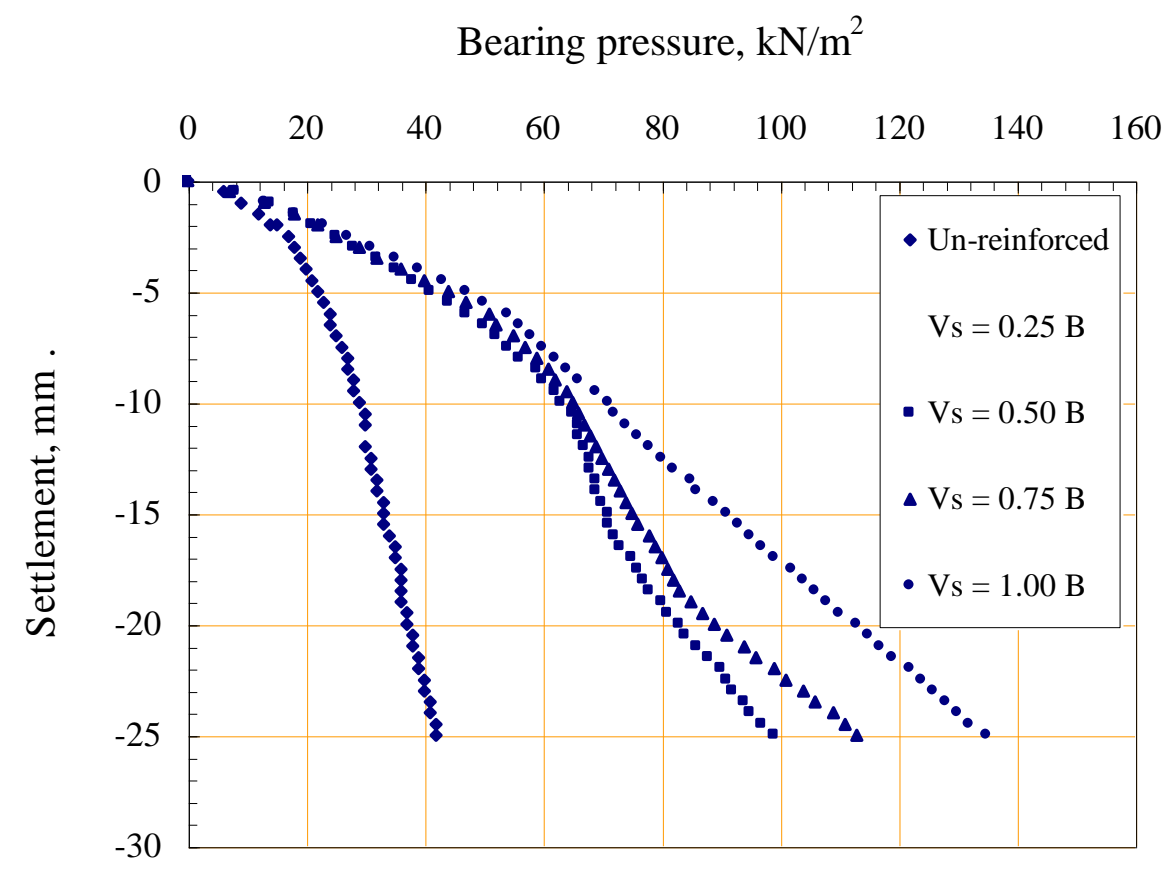

Figure 8: Influence of wrapped cushion thickness on the load-settlement behaviour of reinforced sand beds. 


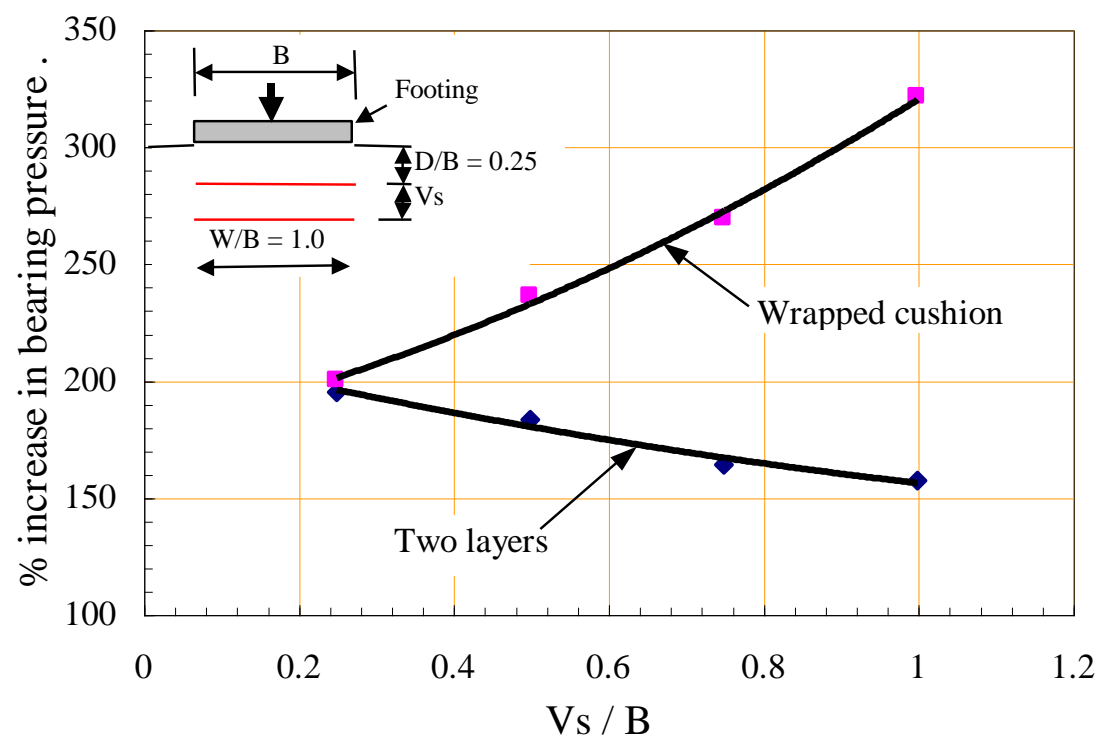

Figure 9: Influence of increasing the vertical spacing between reinforcing layers on the percentage increase in maximum bearing pressure.

The results suggest that there is no optimum value for the thickness of the cushion. However, the behaviour of the reinforced sand bed is significantly affected by the thickness of the wrapped cushion.

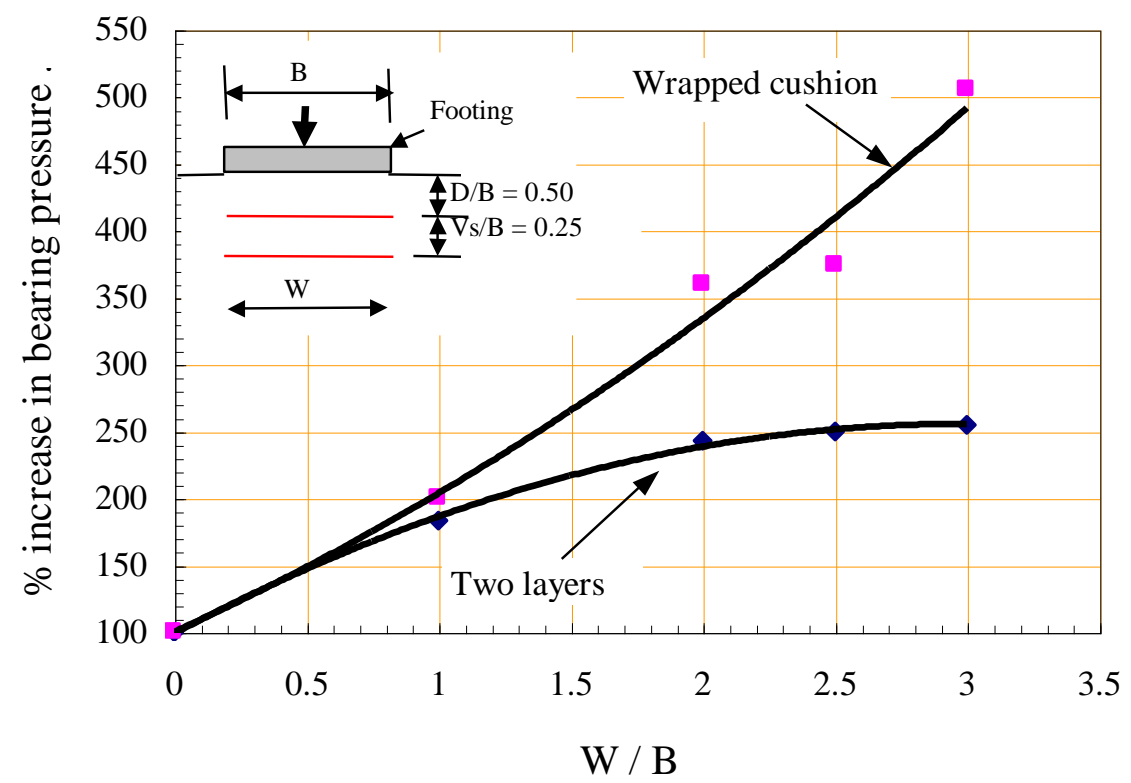


Figure 10: Influence of increasing width of reinforcement on the percentage increase in maximum bearing pressure.

The results of tests aimed at investigating the influence of width of reinforcing layers or wrapped cushions on the percentage increase in maximum bearing pressure are presented in Figure 10. This batch of tests was carried out with a depth of $0.5 \mathrm{~B}$ to the top reinforcement layer and vertical spacing of 0.25 B. Figure 6 shows that the maximum bearing pressure increases when the width of reinforcement increases. It can be seen that there is significant increase in the percentage increase in the maximum bearing pressure when the width of the geotextile layers was doubled. However, it is also observed that there is no significant increase in the maximum bearing pressure with further increase in the width of geotextile layers over 2 B. Similar results were observed by Guido et al (1986) where the optimum width for the geotextile was obtained as $3 \mathrm{~B}$. The increase in the maximum bearing pressure is due to the increase in the mobilised frictional resistance along the geotextile layers.

By increasing the width of the wrapped cushion (W), the maximum bearing pressure increased significantly. This is quite apparent in Figure 10. These results suggested that the increase in the maximum bearing pressure is quite sensitive to the width of wrapped cushion. It should be noted that because of a slight change in the density of the wrapped cushion, there was no significant increase in the maximum bearing pressure when the width of the wrapped cushion increased from $2.0 \mathrm{~B}$ to $2.5 \mathrm{~B}$.

The experimental results suggested that the shear failure zones were not developed directly below the footing, as the depth of the sand is insufficient but instead are developed beneath the cushion. By increasing the width of the cushion the load is redistributed over a larger area and hence, it requires a considerable load in order to fail. In addition, it is observed that large cushions did not settle as one unit but instead the centre of the cushion settled at a quicker rate with the boundary of the cushion being pushed upwards. It is reasonable to conclude that the rate of increase in the maximum bearing pressure for the two types of reinforcement is significantly different with no optimum width of the wrapped cushion. 


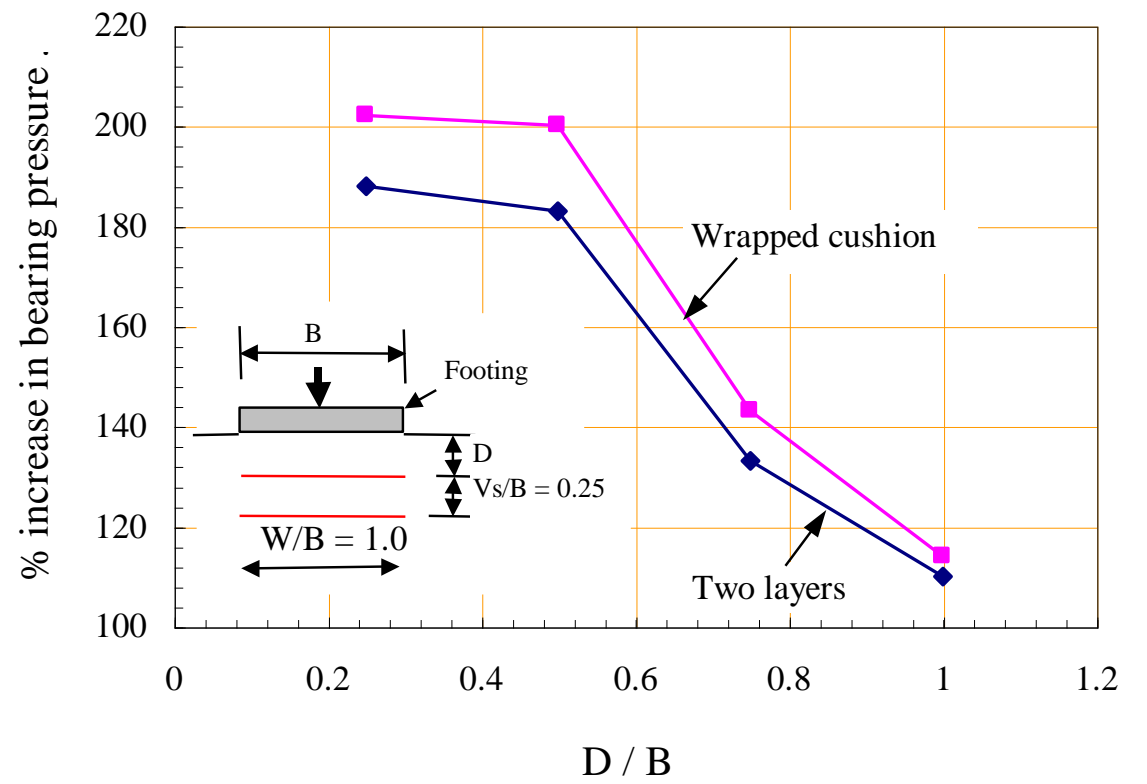

Figure 11: Influence of increasing depth of the top layer on the percentage increase in maximum bearing pressure.

Figure 11 shows the results of increasing depth of top reinforcing layer on the maximum bearing pressure. For both types of reinforcement investigated, the maximum bearing pressure decreased with increasing depth of the top layer. Both of these reinforcement methods displayed a similar behaviour. However, reinforcing sand beds with wrapped cushion showed better performance than reinforcing the sand bed with two layers of geotextile. The maximum improvements for both methods were obtained when the depth of the top layer was at $0.25 \mathrm{~B}$ below the sand surface. Further investigations are underway to examine behaviour of sand beds reinforced with layers and wrapped cushion at smaller depths.

The results show clearly that the behaviour and failure mechanism of sand beds reinforced with wrapped cushions is completely different from those of the conventional soil reinforcement method. The proposed method of reinforcement in which a wrapped cushion with geotextile layer is placed underneath the surface footings seems more effective and beneficial than reinforcing the sand bed with open ended layers of geotextile. 
Conclusions

The following conclusions can be drawn out of the investigation:

- This paper presents a fully coupled numerical analysis of footing-soilreinforcement interaction. The analysis procedures and the material models in the fully coupled analysis are validated by comparison with experimental tests and good agreement is obtained between them. Further numerical studies have been performed using the fully coupled model to simulate the effects of different system parameters

- The results of reinforcing sand beds with two layers of geotextile are in good agreement with previously reported studies.

- An alternative technique is proposed to reinforce the sand bed with a wrapped cushion to utilise the tensile strength of the geotextile sheet.

- At a given value of bearing pressure, the wrapped cushion resulted in smaller settlement than that of the two layers of geotextile. Furthermore, the maximum bearing pressure of wrapped cushion is always greater than that of the two layers of geotextile of the same dimension.

- The behaviour of the two types of reinforcement in respect to the parameter Vs is completely opposite to one another. As the ratio $\mathrm{Vs} / \mathrm{B}$ increases the percentage increase in maximum bearing pressure of sand bed reinforced with two layers of geotextile decreases, whereas that of sand bed reinforced with geotextile cushion increases. The results indicated that there are no signs of optimum value of the thickness of wrapped cushion.

- The width (W) of the reinforcement has a significant effect on the bearing capacity and settlement of the surface footings. The geotextile layers had an optimum width ratio of 2 3 B, after which the bearing capacity did not increase significantly. However, with increasing the width of the geotextile cushion the bearing capacity increases substantially with no signs of an optimum width ratio.

- It seems that the bearing capacity increases with decreasing the depth of the top geotextile layer. However, further research would be required to establish an optimum value. 


\section{References}

Akinmusuru, J.O. and Akinbolade, J.A. 1981. Stability of loaded footings on reinforced soils. Journal of Geotechnical Engineering, ASCE, 107 (6), 819-827.

Alawaji, H.A. 2001. Settlement and bearing capacity of geogrid-reinforced sand over collapsible soil. Geotextile and Geomembranes, 19, 75-88.

Binquit, J. and Lee, K.L. 1975a. Bearing capacity test on reinforced earth slabs. Journal of Geotechnical Engineering, ASCE, 101(12), 1241-1255.

Binquit, J. and Lee, K.L. 1975b. Bearing capacity analysis of reinforced earth slabs. Journal of Geotechnical Engineering, ASCE, 101(12), 1257-1276.

Chang, D. K. (1985). "Bearing capacity of a geogrid-reinforced foundation.” Master's thesis, The Cooper Union, School of Engineering, New York.

Dondi, G., 1994. "Three-dimensional finite element analysis of a reinforced paved road." Proceedings of the Fifth International Conference on Geotextiles, Geomembrane and Related Products, Singapore, pp. 95-100.

Guido, V.A., Dong, K.G. and Sweeny, A. 1986. Comparison of geogrids and geotextile reinforced earth slab. Canadian Journal of Geotechnical Engineering, 23(1), 435440.

Guido, V.A., Dong, K.G. and Sweeny, A. 1986. Bearing capacity of shallow foundations reinforced with geogrids and geoexiles. $2^{\text {nd }}$ Canadian Symposium on Geotextiles and Geomembranes, Edmonton, Alberta, Canada.

Jewel, R.A, Milligan, G. W. E., Sarsby, R. W., and Dubois, D. (1984). "interaction between soil and geogrids." Symp. Polymer Grid Reinforcement in Civil Engineering., London, England, 18-30.

Lee, K.M., and Manjunath, V.R., 2000. "Experimental and numerical studies of geosynthetics reinforced sand slopes loaded with a footing." Canadian Geotechnical Journal, Vol. 37, pp. 828-842.

Michalowski, R.L. and Shi, L. 2003. Deformation patterns of reinforced foundation sand at failure. Journal of Geotechnical and Geoenvironmental Engineering. 129(6), 439-449.

MIZUNO, E. \& CHEN, W. F., Nonlinear Analysis in Soil Mechanics Theory and Implementation, Elsevier Science Publishers B.V, 1990 
Perkins, S.W., 2001. "Numerical modeling of geosynthetic reinforced flexible pavements: final report." Montana Department of Transportation, Helena, Montana, Report No. FHWA/MT- 01-003/99160-2, 96p.

Saleh, N.M. 2001. Experimental evaluation of soil-geotextile interface friction properties. Journal of Engineering and Applied Science, 48 (3), 419-435.

Singh, H. R. (1988). "Bearing capacity of reinforced soil beds," $\mathrm{PhD}$ thesis, Indian Institute of Science, Bangalore, India.

Yamamoto, K. and Otani, J. 2002. Bearing capacity and failure mechanism of reinforced foundations based on rigid-plastic finite element formulation. Geotextile and Geomembranes, 20, 367-393.

Yetimoglu, T., Jonathan T.H. and Saglamer, A. 1994. Bearing capacity of rectangular footings on geogrid-reinforced sand," Journal of Geotechnical Engineering, 120, 2083-2099. 